Artículo de investigación

Apuntes del CENES

ISSN 0120-3053

Volumen $34-\mathrm{N}^{\circ} .59$

enero - junio de 2015

Págs. 63-92

\title{
Efectos de la inversión extranjera directa sobre el crecimiento económico en Colombia: evidencia empírica 2000-2010
}

Effects of foreign direct investment on economic
growth in Colombia: empirical evidence 2000-2010

Efeitos da FDI sobre o crescimento econômicona

Colômbia: Evidências Empíricas2000-2010

María Luz Moyano Buitrago* José Mauricio Gil León**

Fecha de recepción: 10 de febrero de 2014

Concepto de evaluación: 11 de julio de 2014

Fecha de aprobación: 28 de noviembre de 2014

Economista, Profesional en IDU (Instituto de Desarrollo Urbano).Dirección de correspondencia. Calle 20 No.9-20. Bogotá, Colombia. Correo electrónico: marialuz_moyano@hotmail.com

** Economista, especialista en finanzas y Magister en Economía. Docente en el área de Teoría Económica de la Escuela de Economía, UPTC Tunja. Dirección de correspondencia:Calle 39A 6a-00 Tunja, Colombia.

Correo electrónico: mauricio8827@hotmail.com 


\title{
Resumen
}

En este artículo se analiza el efecto de la inversión extranjera directa sobre el crecimiento económico en Colombia, y se muestra que estos flujos causaron efectos, tanto directos como indirectos, en la economía nacional entre el periodo 2000-2010. Así, con el ejercicio econométrico fue posible deducir que los flujos de IED afectaron positiva y moderadamente el crecimiento de la economía Colombiana, y esto permitió concluir que dadas las condiciones de la economía nacional y del clima económico mundial en este periodo, la IED contribuyó al incremento porcentual del PIB y, de la misma manera, a profundizar las coyunturas económicas agregadas y sectoriales que esta trae consigo.

Palabras clave: inversión extranjera directa, crecimiento económico, formación bruta de capital, spillover, economía colombiana.

Clasificación JEL: B22, F21, C22, C67

\begin{abstract}
In this article the effect of FDI on economic growth in Colombia is analyzed, and shown that these flows caused effects, both direct and indirect, in the national economy between 2000-2010. Thus, the econometric exercise was possible to deduce that affect FDI flows and moderately positive growth of the Colombian economy, and this led to the conclusion that given the conditions of the national economy and the global economic climate in this period, FDI contributed to percentage increase in GDP, in the same way, to deepen the aggregate and sectoral economic times it brings.
\end{abstract}

Keywords: Foreign direct investment, economic growth, gross capital formation, spillover, Colombian economy.

\section{Resumo}

Neste trabalho, o efeito do IDE sobre o crescimento econômico na Colômbia é analisado e demonstrado que esses fluxos causou efeitos, diretos e indiretos, na economia nacional entre 2000-2010. Assim, o exercício econométrico foi possível deduzir que os fluxos de IDE crescimento afetado e moderadamente positivo da economia colombiana, e isso levou à conclusão de que, nas con- 
dições da economia nacional e do clima econômico global neste período, o IED contribuiu para aumento percentual do PIB e, da mesma forma, para aprofundar tempos econômicos globais e sectoriais que isso implica.

Palavras-chave: investimento estrangeiro direto, o crescimento econômico, a formação bruta de capital, de repercussão, a economia colombiana.

\section{INTRODUCCIÓN}

Los flujos de inversión extranjera directa (IED) en Colombia son, sin duda alguna, uno de los principales temas dentro de las discusiones y agendas de la economía nacional actual. Su creciente dinamismo, con registros de repunte desde el año 2004 (especialmente gracias a la favorable coyuntura internacional), la ha convertido en una de las principales fuentes de financiación de la economía colombiana, así como en un importante determinante de su cuenta de capital, mercado cambiario $\mathrm{y}$, consecuentemente, de su crecimiento económico (Garavito, Iregui \& Ramírez, 2012). Esto se ha reforzado con medidas de política económica adoptadas durante los últimos veinte años para estimular la IED y, que a su vez, le han permitido tener un impacto cada vez mayor sobre la economía, especialmente después de consolidada la apertura económica en la década de los 90's y la posterior estrategia de "confianza inversionista" a partir del año 2002.

En este contexto, Colombia ha sido un país con singulares características ${ }^{1}$ que han mejorado su potencial de atracción para este tipo de inversiones ${ }^{2}$, y con ello, para sus beneficios y riesgos. El país ha venido reforzando sus estrategias de crecimiento económico con base en el

Colombia hace parte de una región (Andina y Latinoamericana) con grandes ventajas comparativas -bajo la luz de la teoría de la localización- respecto a los países origen de la IED. Es un país que posee ventajas locales como materias primas específicas, mano de obra con costos menores respecto a los países inversionistas, etc., (Guerra, 2001), así como el manejo de incentivos como Zonas Francas, contratos de estabilidad jurídica e incentivos fiscales (Coleman, 2012)

2 Colombia ha implementado muchas reglamentaciones para poder atraer mayor inversión extranjera. El saldo de IED que Colombia ha captado (33,1\% del PIB en 2006) está ligeramente por encima del latinoamericano (30 \% del PIB) y el de las economías en desarrollo (26,7 \% del PIB) (Fedesarrollo, 2007). 
comercio internacional con el modelo económico de apertura desde 1991, bajo la convicción de que la presencia de este tipo de inversiones no sólo atraen capital externo al país, sino que estos generan importantes réplicas positivas sobre el empleo, la transferencia de tecnología, la formación de capital, la calificación de la mano de obra, la productividad de los sectores, las exportaciones, la competitividad y, en general, el bienestar de la economía en el largo plazo. Como menciona la CEPAL (2004), esto se da bajo la concepción paradigmática que sostiene que la apertura de los mercados locales hacia el exterior, la limitación del sector público, la reducción de la intervención gubernamental en la actividad productiva, la formación bruta de capital, la distribución y el financiamiento, son requisitos para la asignación eficiente de recursos y para lograr el desarrollo económico.

Sin embargo, la suerte de cada país respecto a las externalidades que genera la IED sobre sus economías no es la misma. Para Colombia, la mayor parte de los ingresos por IED son resultado de transferir activos nacionales a extranjeros y no de formación bruta de capital fijo y creación de empresas productivas(Banco de la República de Colombia, 2010); la repatriación de utilidades ${ }^{3}$ sobre la cuenta corriente limita sus efectos, dado que más del $70 \%$ de las utilidades de las empresas extranjeras son repatriadas y no más del $30 \%$ son nuevamente invertidas en
Colombia (Banco de la República de Colombia, 2010); además, los recursos por IED, en su mayor parte, son destinados a financiar el déficit de balanza de pagos y el desarrollo industrial no ha sido jalonado como se esperaría.

De esta manera, muchas de las evidencias de la participación de la IED dentro del crecimiento económico del país han llevado a que surjan ambigüedades frente a la causalidad y la magnitud de esta relación. Con el fin de aportar al análisisde las implicaciones que trae para el país los acervos de capital extranjero, el objetivo de este estudio es determinar los principales efectos de la IED sobre el crecimiento económico en Colombia entre los años 2000 y 2010, teniendo en cuenta las variables asociadas para el corto plazo como la formación bruta de capital, la apertura económica, gasto público, cartera financiera y, por supuesto, la IED. Adicionalmente, y puesto que las externalidades de la IED se presentan mediante diversos canales, en este análisis también se hace una revisión particular de los encadenamientos sectoriales que esta puede generar.

El estudio se divide en cuatro secciones, además de esta introducción, donde se buscará abordar todas las dimensiones de la temática para lograr responder al planteamiento inicial y delimitar la indagación. En la primera sección se procederá con un análisis descriptivo con base en

Para el caso del sector petróleo, no menos del 99.0\% de las utilidades son repatriadas dejando una nueva inversión en el país de solo el 1.0\% (Banco de la República de Colombia, 2010). 
la recopilación de algunos de los aportes teóricos más significativos del comercio internacional y del crecimiento y desarrollo económico, entendiendo el funcionamiento de las principales variables que interesan en el estudio como la IED y el crecimiento económico. Igualmente, se identificarán los principales exponentes de esta área en estudio, así como de sus contribuciones teóricas hacia las convergencias y divergencias en la relación de las variables que interesa abordar.

En la sección dos se describirá la evidencia empírica de algunos de los principales efectos e impactos de la IED sobre el crecimiento económico en el ámbito colombiano, utilizando información estadística disponible para el periodo 2000-2010, al igual que de exposiciones gráficas que serán de importante apoyo para su ilustración y contextualización.

En la tercera secciónse buscará estimar el efecto de la IED sobre el crecimiento económico de la economía colombiana para el periodo de estudio, junto a las principales variables que explican el crecimiento económico en el corto plazo. Para llevar a cabo este propósito, se trabajará mediante un modelo econométrico que introducirá los saldos de IEDen relación a las salidas por dividendos y utilidades para lograr una estimación más precisa, esperando lograr un acercamiento más certero para la aclaración de la ambigüedad existente. Complementario a esto, se abordará el análisis sectorial por medio del desarrollo de una simulación conla matriz insumo- producto de Colombia para observar el impacto de la entrada de IED en sectores claves, tanto para la inversión extranjera como para la economía en su totalidad. Finalmente, se presentan las conclusiones.

\section{LA IED Y EL CRECIMIENTO ECO- NÓMICO}

La relación teórica entre IED y crecimiento económico va a diferir según los marcos de análisis utilizados. Un primer análisis puede empezarse a dar por los modelos de crecimiento neoclásicos, que involucran a la IED en una relación neutral hacia el crecimiento económico en el largo plazo, donde se encuentran supuestos de mercados de competencia perfecta, productividad marginal decreciente y retornos constantes a escala. Así, los incrementos exógenos de la IED sólo pueden afectar positivamente el capital por persona transitoriamente, dados los retornos decrecientes. Por lo tanto, se analiza como única vía de impacto hacia el crecimiento económico en el largo plazo, la modificación de la tecnología y el trabajo como factores exógenos (Álvarez, Barraza \& Legato, 2009).

De otro lado, la literatura referente a los modelos de crecimiento endógeno señalan que la IED tiene un efecto positivo de manera indirecta sobre en crecimiento económico por medio de la formación de capital y del desarrollo de recursos y capital humano. Uno de los factores determinantes de los efectos que la IED sobre el crecimiento económico es a través de 
los denominados spillovers ${ }^{4}$ o externalidades positivas, reflejadas principalmente en la transferencia de tecnología desde los países más desarrollados hacia los receptores de los flujos (Murra, 2006). En otras palabras, los países esperan que sus empresas se beneficien de spillovers positivos en productividad causados por la presencia de empresas multinacionales ${ }^{5}$, las cuales se supone tienen un mayor nivel de desarrollo tecnológico. Los principales mecanismos de los spillovers se presentan mediante distintos canales como los efectos demostración (la entrada de empresas extranjeras puede demostrarle al país anfitrión la existencia y rentabilidad de adquirir nuevas tecnologías), los efectos competencia (las empresas multinacionales pueden ubicarse en sectores caracterizados por altas barreras a la entrada porque cuentan con economías a escala), los efectos de la movilidad de trabajadores entre firmas, los efectos de los encadenamientos verticales (referente al incremento de la productividad de las firmas locales como resultado de ser proveedoras o clientes de las multinacionales), los efectos sobre proveedores (incrementando los estándares de calidad de sus insumos) y, finalmente, los efectos sobre los clientes (mayor disponibilidad de insumos) (Murra, 2006).

No obstante, dichos efectos estarían condicionados a la existencia de ciertos factores en el país de destino, como lo es el nivel mínimo en capital humano. Otros de los factores condicionantes pueden darse en el desarrollo del mercado financiero de la economía receptora, el grado de apertura que maneje esta economía, su nivel de ingreso y sus condiciones distributivas (Lensink, 2003).

Por otro lado, consideraciones sobre la IED han llevado a identificar procesos de convergencia entre los países que interactúan en el mercado de capitales; donde se señala que existe una tendencia condicionada de las economías y que el capital tiende a desplazarse desde países con bajos retornos marginales hacia países con tasas mayores; o lo que es lo mismo, de países desarrollados a países en vía de desarrollo (Álvarez, Barraza \& Legato, 2009). Como lo mencionaFajnzylber (1976), “La expansión de la actividad económica estuvo acompañada desde un principio de las grandes corrientes de capitales que se desplazaban según las exigencias de la propia actividad económica a nivel mundial". Un interesante estudio de este fenómeno es el aportado por Galindo y Escont ${ }^{6}$, donde prueban que los países menos desarrollados tienden a la convergencia con los desarrollados creciendo más rápidamente, pero bajo condiciones de convergencia en educación, fuerza laboral, inversión extranjera, estructura de precios y la tasa de inversión

$4 \quad$ Referente a las externalidades, tanto positivas como negativas, derivadas de las actividades de las empresas multinacionales y de economías de escala, producto de la IED.

5 Inversión extranjera directa de flujos internacionales de capital en los que una empresa de un país (inversionista) crea o amplía una filial en otro país (receptor) y cuya característica distintiva está enmarcada en que es una inversión que no solo implica una transferencia de recursos, sino también la adquisición de control (Krugman \& Obstfeld, 2001).

$6 \quad$ Citado por Álvarez, Barraza y Legato, 2009, referente al estudio de flujos internacionales de capital, convergencia y crecimiento, publicado en el año 2004 por TheJournal of EconomicAsymmetries. 
fija; esto si los niveles de liquidez y riesgo de los países estudiados están dentro de un margen similar (Álvarez, Barraza \& Legato, 2009) ${ }^{7}$.

Sin embargo, la IED puede tener efectos negativos sobre el crecimiento económico, como es el caso de la existencia de distorsiones financieras y comerciales ${ }^{8}$ (Lipsey, 2000), así como los límites y condicionamientos (mencionados anteriormente) de las economías receptoras para hacer de esta una variable a favor de su crecimiento.

\section{Determinantes de la IED}

Tanto la magnitud como el direccionamiento de los flujos de IED dependen de las percepciones de costos y beneficios que han de ofrecer las alternativas analizadas. Algunas teorías ${ }^{9}$ subrayan el papel que tienen estos incentivos en el momento de tomar las decisiones de inversión de una empresa extranjera, las ventajas y desventajas que puede enfrentar en el potencial país receptor. Es así como este tipo de factores van complementando las condiciones propias de la localización de la IED, tanto en ámbitos económicos y políticos como institucionales. Estas características se van moldeando como determinantes de la capacidad de atraer IED por parte del país receptor, así como características importantes en las determinaciones de inversión.

Dentro del estudio de las pautas de localización de las empresas, se resaltan como los determinantes más comunes los que hacen referencia al tamaño del mercado y a su potencial de crecimiento, los factores relativos a la afinidad social y cultural, la estabilidad del mercado del país al que se dirige la inversión, el sistema económico y político y la capacidad de las empresas y economías locales de mantener sus barreras de entrada (Ramírez \& Rincón, 2010).

De esta manera, los principales factores que determinan los cauces de los flujos de capital extranjero pueden enfocarse en cuatro categorías específicas:

- La coyuntura económica mundial, regional y de origen de los flujos de capital.

- Los factores que influyen en la decisión de invertir de las empresas multinacionales. Esta característica está enfocada en las decisiones de localización, en los balances de ventajas y desventajas del país receptor respecto a costos y beneficios esperados de la inversión (Cubillos \& Navas, 2000). Dentro de los costos se pueden caracterizar los de producción (factores de trabajo, capital físico

\footnotetext{
Para el caso de algunas economías, los flujos de inversión extranjera resuelven los crónicos estrangulamientos de la balanza de pagos, sirviendo como importante alentador del crecimiento y su condicionamiento hacia la convergencia (Ibarra, 2004).

8 Un ejemplo de estas distorsiones se presenta, por ejemplo, con la entrada de los llamados "capitales golondrina" los cuales, por su característico corto periodo de presencia, crean plataformas especulativas y no generan externalidades sólidas como la consolidación de algún sector gracias a su financiación. De la misma manera, cuando los capitales no logran generar ambientes propios de exportación o aperturas comerciales eficientes.

9 Teoría de la organización industrial.
} 
y humano, tierra), los de los insumos, (servicios públicos y combustibles), las materias primas, los de transporte y comunicaciones, los de transacción y los tributarios (Cubillos \& Navas, 2000).

- La capacidad competitiva de un país para atraer la inversión extranjera. Esta capacidad puede ser medida mediante la dotación de factores, la disponibilidad de tecnología, el tamaño del mercado, las preferencias de los consumidores, la diferenciación de productos y eventuales economías de escala (Fedesarrollo, 2007). De la misma manera, se considera especialmente importante un marco institucional que garantice una eficiente asignación de los recursos, logre un equilibrio político ${ }^{10}$ y social sostenible, preserve la estabilidad macroeconómica y establezca una regulación clara para la IED (Lahiri, 2009) ${ }^{11}$; un gobierno con credibilidad; un mercado de cierta magnitud, con perspectivas de expansión y mínimas distorsiones; un adecuado ingreso per cápita; una política comercial que consiga acceso a mercados regionales y globales, así como la existencia de ventajas comparativas en dotación de recursos naturales ${ }^{12}$, infraestructura, mano de obra, capital humano y otros factores como el conocimiento que impulsan la generación de externalidades positivas (Cubillos \& Navas, 2000). A lo anterior se hace necesario sumar la profundidad de los mercados financieros ${ }^{13}$, la favorabilidad de los regímenes laborales y tributarios y la calidad de las instituciones.

- Las políticas públicas e incentivos que ofrecen las economías receptoras de los flujos de capital. Este tipo de características adoptan su importancia en la medida en que "actúan sobre el marco institucional y el orden económico, político y social, la política económica, la estructura de mercado y los incentivos para la acumulación de factores y la provisión de bienes públicos, y además mediante la generación deliberada de estímulos para atraer inversión extranjera" (Proexport, 2007). En esta medida, la política fiscal, comercial y financiera otorgan importantes incentivos para la IED por medio del otorgamiento de ventajas tributarias y focalización del gasto público, de los tratados y preferencias y por medio de condiciones especiales de créditos (Cubillos \& Navas, 2000) ${ }^{14}$.

\footnotetext{
En Colombia el régimen legal de IED se ha ido transformando desde comienzos de los años noventa como resultado de la transición de una economía virtualmente cerrada al capital foráneo a una economía abierta con una política activa de atracción de IED (Proexport, 2007).

12 Dependiendo de la actividad que realice la empresa de capital extranjero, algunos países resultarán comparativamente más ventajosos que otros en recursos naturales por cuanto esto se traduce en mayores yvariadas fuentes de materias primas, facilidad de adquisición y acceso a ellas, así como un mejor manejo de costos dentro del proceso productivo.

13 Especialmente la profundidad en lo que se refiere a mercados financieros domésticos (Cubillos \& Navas, 2000).

14 En la política hacia la IED en Colombia se puede distinguir tres etapas. La primera, una actitud relativamente hostil de las autoridades y una legislación restrictiva, coherente con el modelo de sustitución de importacione; la segunda, la etapa de "atracción pasiva" la cual se dio a inicios de los noventa; y la tercera, "la acción activa" desde comienzos del siglo XXI (Proexport, 2007).
} 
Por otro lado, Dunning (2001) propone el paradigma ecléctico OLI(Ownership, Locational e internalization), donde se realiza un trabajo de reconocimiento de los diferentes factores que motivan a una empresa a ejecutar una expansión internacional de sus actividades. El paradigma establece que la internacionalización fundamentalmente se debe a las ventajas de propiedad, localización y de internalización. En cuanto a las ventajas de propiedad, se refiere a la acumulación de activos específicos o con sus características tecnológicas o de producto, las cuales son específicas de la empresa y puede generar más presión en sus competidores nacionales en mercados anfitriones.
Las ventajas de localización se refieren a los factores productivos e institucionales que se manifiestan en una zona geográfica determinada, existiendo una ventaja potencial de ser capaz de integrar actividades entre sectores del mundo con costos de factores y costos de recursos muy diferentes. Y, finalmente, las ventajas de internalización son las que se derivan de explotar internamente activos específicos en lugar de hacerlo en el mercado externo, con la construcción de economías de escala y alcance mediante actividades internacionalizantes dispersas a lo largo de las fronteras, que de otro modo, se repartirían entre numerosas empresas (Ramírez \& Rincón, 2010).
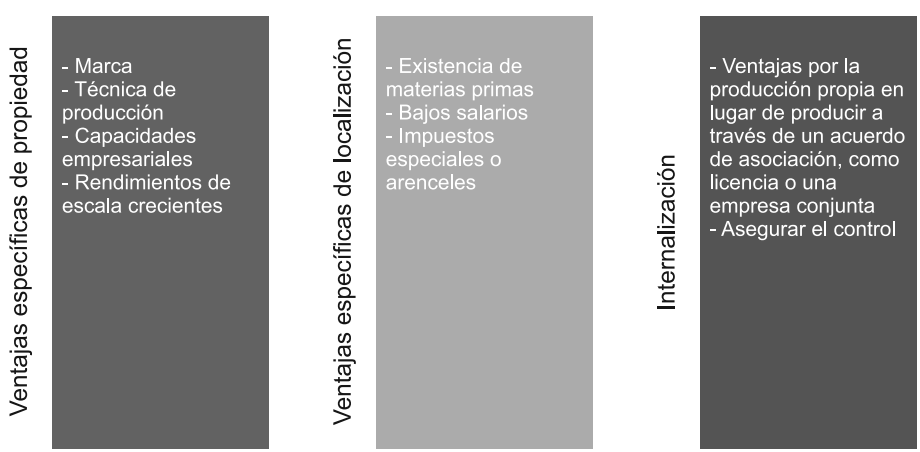

Figura 1. La OLI de Dunning

Fuente: Coleman (2012)

\section{LA IED EN COLOMBIA}

\section{La legislación de la IED en Colombia}

El régimen legal colombiano ha sido objeto de importantes cambios a lo largo de la historia económica del país. $\mathrm{Su}$ transformación se ha venido dando en varios periodos marcados por fuertes transiciones económicas y sociales sobre el contexto nacional y mundial ${ }^{16}$; dentro de las que se puede destacar el

\footnotetext{
16 Por ejemplo, la apertura al capital extranjero ocurrió en un momento en el cual el mundo entero cambió su legislación a favor de la IE. También han influido cambios globales en las estrategias de desarrollo, como la liberalización de los mercados (Steiner \& Giedion, 1995).
} 
abandono del modelo de sustitución de importaciones y, más adelante, el paso a la apertura económica. Es así como la legislación colombiana ha ido de una economía virtualmente cerrada al capital foráneo a una economía abierta con una política atractiva de atracción de IED (Fedesarrollo, 2007).

Una primera etapa de este análisis se extiende desde finales de los años sesenta hasta comienzos de los años noventa. Con el estatuto cambiario (Decreto-Ley 444 de 1967), la legislación del primer periodo ha de reflejar la preocupación y las medidas adoptadas por los posibles efectos negativos de la inversión extranjera sobre la balanza de pagos, así como el riesgo por la suplantación del capital nacional por el extranjero. Con este decreto se dio un largo periodo de restricción de la inversión extranjera (IE) en concordancia con el modelo de sustitución de importaciones el cual promovió el desarrollo productivo principalmente a partir de recursos domésticos. "Al tiempo que se reconocía la importancia de la IED como complemento del ahorro y como mecanismo de transferencia de tecnología, se consideraba que podía tener efectos adversos en la balanza de pagos y que el país podía beneficiarse si lograba canalizar la IE según sus necesidades" (Steiner \& Giedion, 1995).

La crisis de la deuda en los años ochenta impuso un cambio en la evaluación de la IE y se empezó a dar una transición en las restricciones. Volvieron a primar los aspectos positivos en los sectores que podían recibir IED y en la libertad de transferencia de capital y utilidades, con una sucesiva simplificación de los trámites relacionados y la repatriación de utilidades y capital (Steiner \& Giedion, 1995).

La segunda etapa puede identificarse a comienzos de los años noventa con la apertura económica. En 1991 se expidió la Ley 9 que bajo la modalidad de Estatuto Cambiario estipularía las normas generales del régimen de inversión extranjera en el país enmarcadas en un proceso de internacionalización de la economía con libre flujo de capitales. La IED empezó a ser considerada como un factor importante para el desarrollo económico de Colombia por cuanto la reforma del régimen de IED se basó en su reconocimiento. La ley eliminó toda restricción para invertir en cualquier sector o actividad económica exceptuando la seguridad y defensa el sector inmobiliario, así como el manejo de los residuos tóxicos, radioactivos o peligrosos $^{17}$ (Suárez, 2010).

Así, la Ley 9 de 1991 estableció como principios fundamentales la igualdad en el tratamiento entre nacionales y extranjeros, universalidad de acceso a los sectores, y automaticidad en la aprobación (Steiner \& Giedion, 1995). Sin embargo, la potestad se mantuvo para

\footnotetext{
En algunos sectores se mantuvieron restricciones parciales de IE como en los sectores de telecomunicaciones y transporte aéreo y marítimo (Fedesarrollo, 2007).
} 
regular los movimientos de capital por lo que se hizo una importante diferenciación entre la forma directa y la modalidad de portafolio ${ }^{18}$. De igual manera, se concedió el trato nacional a los extranjeros con excepción de la transferencia de utilidades (la cual se sujetó a límites y condiciones impuestas por el gobierno nacional (Suárez, 2010).

La tercera etapa comprende lo que va de este nuevo siglo. Así, la profundización de las reformas al régimen de IED y su cada vez mayor simplicidad y mejores condiciones para la atracción de capitales foráneos, es una importante característica de las estrategias económicas actuales.

En los últimos años el gobierno ha buscado que la regulación responda a las necesidades del inversionista extranjero a las nuevas formas alternativas de inversión que han ido surgiendo con el desarrollo de los mercados de capitales. No obstante, todavía la en la legislación hay una división entre inversión directa y portafolio que restringe formas de inversión basadas en innovaciones financieras y en general mecanismos de participación en el capital de empresas domésticas alternativos a los usados tradicionalmente. (Fedesarrollo, 2007)
Con el Gobierno de Andrés Pastrana se fijó el Decreto 2080, también conocido como el Régimen General de Inversiones de Capital del Exterior en Colombia y de Capital Colombiano en el Exterior. En este se reitera el trato nacional a la inversión extranjera, la redefinición de las formas y los modos de inversión extranjera, el registro de la IE, y de acuerdo con lo establecido en 1991, se abordaron como regímenes especiales para estas inversiones los sectores financiero, de hidrocarburos y de minería y el de portafolio (Suárez, 2010).

El 8 de junio de 2005 se aprobó la denominada Ley de Estabilidad Jurídica para los Inversionistas en Colombia (Ley 963), en la cual se establecen los contratos de seguridad jurídica y garantías para los inversionistas mediante el mejoramiento de la figura de las zonas francas especiales. No obstante, se ha criticado las dificultades de la falta de creación de los criterios para la aprobación de las solicitudes; así como el papel que juegan las zonas francas en la generación de empleo ${ }^{19}$.

Finalmente, uno de los incentivos más grandes que le ha dado la legislación colombiana a la IE está dado a partir de la Ley 1111 del 27 de diciembre de 2006, donde se eliminael impuesto del $7 \%$ para las remesas que por todo concepto los inversionistas enviaran al exterior ${ }^{20}$.

18 La modalidad de portafolio es la que va dirigida al mercado de valores.

19 Para la declaración de zonas francas empresariales en Colombia, los requisitos señalan que a mayor capital se exija menor número de plazas de trabajo, lo cual sesga a este tipo de instalaciones a ser intensivas en maquinaria y equipo y no en mano de obra (Suárez, 2010).

20 Esta medida ha afectado las finanzas públicas del país puesto que el recaudo (paralelo a las remisiones de utilidades) es el resultado de un efecto neto no tan grande de la IED en Colombia. "De los 9.040 millones de dólares que entraron en el año 2007 volvieron a salir 7.534 por repatriación de utilidades"(Suárez, 2010). 
Dinámica de la IED en Colombia durante los años 2000-2010

El proceso de apertura económica, que no solo eliminó las barreras al capital externo, sino que abrió nuevas oportunidades de inversión para el sector privado, se agudizó con la importante afluencia de IED a mediados de los años noventa ${ }^{21}$. Sin embargo, finalizando esta misma década, la crisis financiera internacional, la complicada situación política y de orden público, la finalización del auge de privatizaciones y la recesión económica que experimentó el país desde 1999, desestimularon la afluencia de recursos de inversión extranjera a Colombia hasta los primeros años del 2000 (Fedesarrollo, 2007).
Para la primera década del siglo XXI, la IED fue fluctuante pero mostrando una tendencia de aumento constante (Figura 2). Entre los años 2000 y 2003, los ingresos y egresos por IED se vieron afectados por el debilitamiento coyuntural de la economía mundial, en especial de los países desarrollados donde se concentra gran parte de estos flujos. En el año 2008 alcanzó un máximo de US\$10.596 millones y en el año 2006 se registró un bajo nivel de US\$6.656 millones. La tendencia general al alza suele atribuírsele a varios factores, dentro de los que se encuentran las políticas y regulaciones implementadas por el gobierno para la atracción de mayores niveles de inversión, así como la suscitada confianza inversionista, dadas las mejoras en la seguridad dentro de todo el territorio nacional (Coleman, 2012).

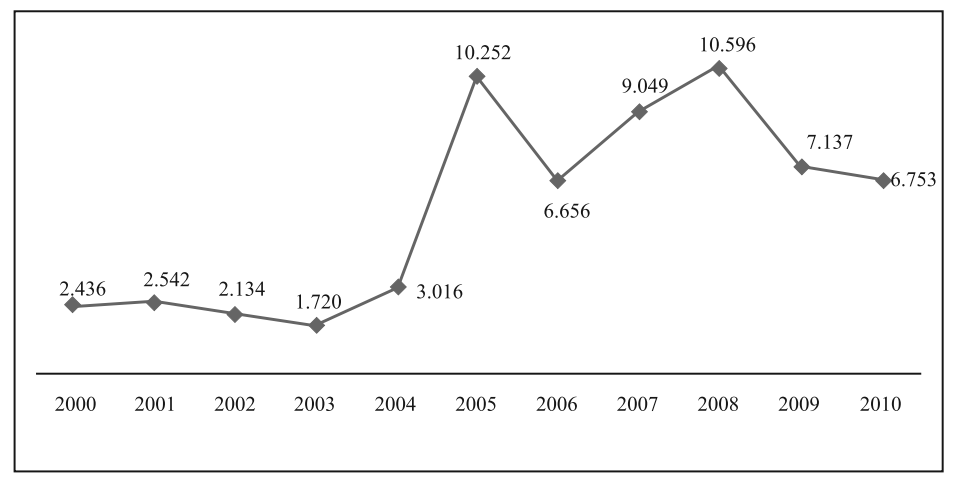

Figura 2. Inversión extranjera directa de Colombia (2000-2010) (millones de dólares)

Fuente: Banco de la República. Subgerencia de Estudios Económicos-Balanza de Pagos.

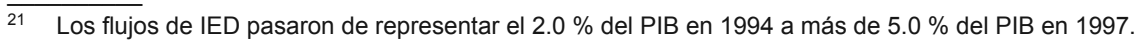


De la misma manera, la crisis económica y financiera que inició a comienzos del 2008 perturbó la IED en todo el mundo. Esta dio lugar la reducción de las perspectivas de crecimiento económico (determinante fundamental de la IED), restringió el acceso a los recursos financieros nacionales y extranjeros y aumentó la incertidumbre y el panorama de riesgos. Sin embargo, a pesar de la inestabilidad del clima económico mundial, la región alcanzó importantes niveles de flujos de inversión extranjera gracias al buen desempeño de las economías latinoamericanas y a las industrias ligadas a la extracción de recursos naturales (Coleman, 2012). Además, la IED continuó entrando al país, amortiguando la reducción de otros flujos de capital ocurrida durante este periodo.

En el año 2005, uno de los años donde mayor flujo se registró dentro de la década, más de la mitad de la inversión extranjera llegó al país en el cuarto trimestre debido principalmente al buen clima económico por el que el país empezó a experimentar, de hecho, el monto anual es muy superior al ingreso por este concepto del que se ha presentado año a año desde 1994 (Suárez, 2010). Así, desde este año los flujos empezaron a llegar con fuerza, por lo que se puede evidenciar una transición de flujos muy superior a los primeros años del decenio.

Sin embargo, es importante examinar los flujos de IED paralelamente con los giros de los dividendos y utilidades (los cuales, al igual que las entradas de inversión extranjera, han sido de importantes cuantías) para tener un análisis un poco más profundo de su comportamiento neto. En la Tabla 1 se puede apreciar la proporción anual de los egresos por beneficios contra los ingresos por inversión y, donde es evidente, se dio en este periodo una relación con tendencia a ser uno a uno.

Como puede observarse, la tendencia de esta relación a lo largo de este periodo ha venido reduciéndose. Para el año 2000, la relación entre el monto de inversión extranjera directa y los egresos por pago de utilidades y dividendos fue de 3.6; esto es, se invertían 3,6 por cada uno que salía. Para los años siguientes, la reducción de esta relación empezó a consolidarse hasta el 2005 (Suárez, 2010), donde regresó a la alza con un 2.86. En los últimos años, la relación nuevamente ha venido declinando, por lo que a finales del periodo la salida por rentas es mayor que las entradas por inversión de capital, siendo la relación 0.66 . 
Efectos de la inversión extranjera directa sobre el crecimiento económico ...

María Luz Moyano Buitrago - José Mauricio Gil León

Tabla 1. Relación del monto de IED y egresos por pago de utilidades y dividendos

\begin{tabular}{|c|c|c|c|}
\hline \multicolumn{3}{|c|}{$\begin{array}{c}\text { Relación entre el monto de la inversión extranjera directa (IED) y los egresos } \\
\text { por pago de utilidades y dividendos - Colombia (2000-2010) }\end{array}$} \\
\hline ANO & $\begin{array}{c}\text { IED (MILLONES } \\
\text { DE DÓLARES) }\end{array}$ & $\begin{array}{c}\text { GIROS DE DIVIDENDOS } \\
\text { Y UTILIDADES } \\
\text { (MILLONES DE DÓLARES) }\end{array}$ & $\begin{array}{c}\text { RELACION } \\
\text { ENTRE IED/GIROS }\end{array}$ \\
\hline 2000 & 2,436 & 674 & 3.61 \\
2001 & 2,542 & 938 & 2.71 \\
2002 & 2,134 & 1,070 & 1.99 \\
2003 & 1,720 & 1,525 & 1.13 \\
2004 & 3,016 & 2,453 & 1.23 \\
2005 & 10,252 & 3,585 & 2.86 \\
2006 & 6,656 & 4,615 & 1.44 \\
2007 & 9,049 & 6,667 & 1.36 \\
2008 & 10,596 & 8,152 & 1.30 \\
2009 & 7,137 & 7,719 & 0.92 \\
2010 & 6,753 & 10,164 & 0.66 \\
\hline
\end{tabular}

Fuente: Banco de la República.

\section{Flujos de la inversión extranjera directa en Colombia por sector}

La distribución sectorial de los flujos de IED muestra que en los últimos años los recursos de inversión extranjera se han concentrado en unos sectores específicamente. La composición sectorial promedio de los flujos de IED en el periodo 2000-2010 muestra que la mayor parte de los recursos se concentraron en el sector petróleo, atraídos por los altos precios internacionales del crudo y la mejora de los términos contractuales (Coleman, 2012), con una participación total de $26 \%$. De la misma manera, el sector de minas y canteras y la industria manufacturera han sido receptores de una importante parte de estos recursos con un $23 \%$ y $20 \%$ respectivamente. Así, el alto nivel y aumento de los precios de las materias primas y la legislación favorable, han traído a muchos inversionistas externos a las actividades del sector primario especialmente, y ha concentrado estos recursos en unos pocos sectores de la economía colombiana.

\section{Fuentes de inversión extranjera en Colombia 2000-2010}

Tradicionalmente Colombia ha recibido grandes niveles de capital foráneo de países como Estados Unidos, España y Holanda (Coleman, 2012). La Figura 4 muestra la distribución de los principales países que invirtieron en Colombia entre el 2000 y el 2010. En este periodo, el 58\% de la inversión provino de los Estados Unidos (27\%), Inglaterra (14\%), Panamá (9\%) y España (8\%). 
En el año 2007, de cada 100 empresas multinacionales instaladas en Colombia, 25 fueron procedentes de los Estados Unidos, registrando ingresos operacionales por US $\$ 10,857$ millones, lo cual equivale al $6.3 \%$ del PIB colombiano.
De la misma manera, los registros indican que para este año, el $10 \%$ de las ventas de las principales 1000 empresas del país representaron el $5 \%$ del total de la recaudación de impuestos y el $10 \%$ de las exportaciones totales (Coleman, 2012).

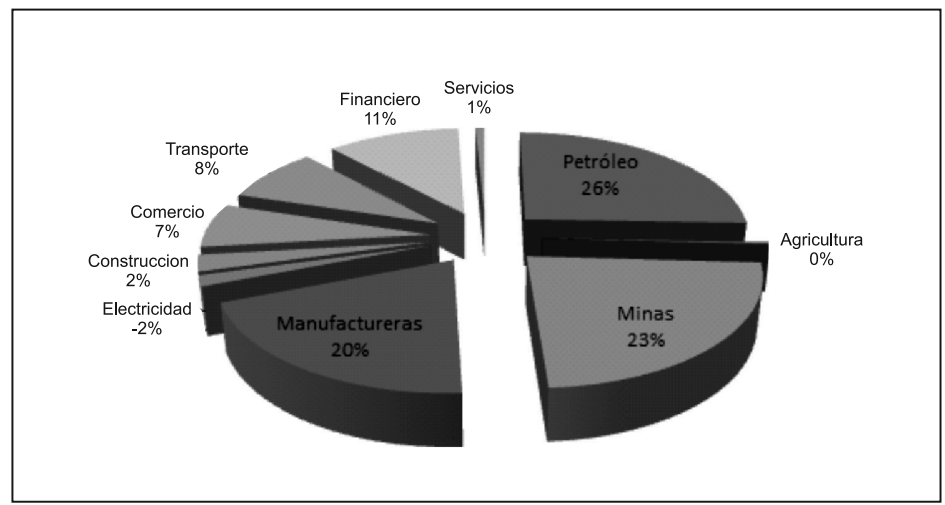

Figura 3. Composición sectorial promedio de los flujos IED 2000-2010

Fuente: Banco de la República, Subgerencia de Estudios Económicos-Balanza de Pagos

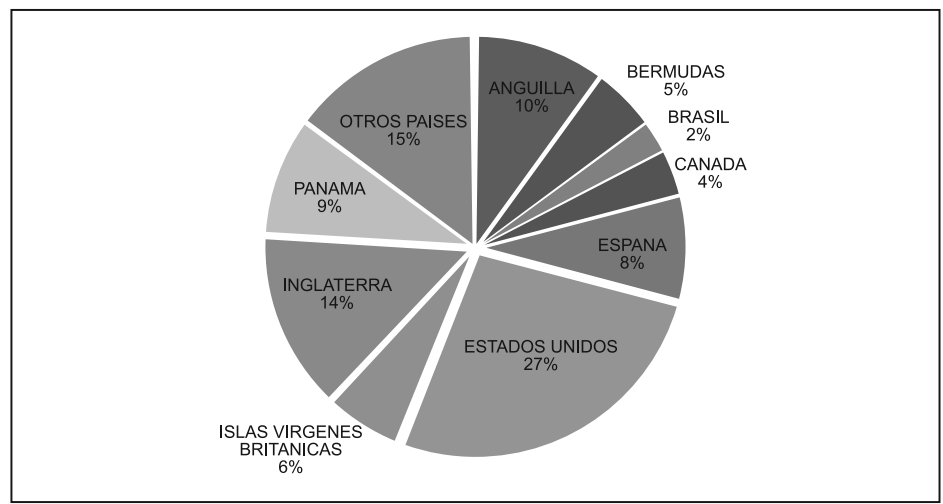

Figura 4. Fuentes de inversión extranjera en Colombia

Fuente: Banco de la República, Subgerencia de Estudios Económicos 
Efectos de la inversión extranjera directa sobre el crecimiento económico ...

María Luz Moyano Buitrago - José Mauricio Gil León

\section{ANÁLISIS EMPÍRICO}

A lo largo de la literatura sobre IED se puede encontrar diversidad de estudios y posiciones acerca de la causalidad y magnitud de los efectos, directos e indirectos, de las inversiones extranjeras sobre el crecimiento de las economías que las reciben. Para analizar el efecto de la IED se realizó un análisis tanto a nivel agregado como sectorial.

Primero, se trabajó un modelo econométrico enfocado en el comportamiento histórico de la IED sobre el crecimiento de la economía colombiana, así como de la incidencia de otras variables para fortalecer la observación. De la misma manera, y para complementar el análisis, se realizó un ejercicio sectorial usando la matriz insumo-producto de Colombia para identificar la importancia de la inversión extranjera dentro de los encadenamientos hacia delante y hacia atrás de sectores claves sobre sectores relacionados, y poder observar su impacto sobre la economía.

\section{Análisis macroeconómico}

Como se ha mencionado a lo largo del documento, dentro de los determinantes del crecimiento económico de un país, la afluencia de inversión extranjera a la economía puede derivarse en efectos positivos; sin embargo, es necesaria la consideración de otras variables para poder medir progresivamente el comportamiento del PIB, y así complementar el análisis.
Es así como existen diversos factores que pueden afectar el crecimiento económico de un país. Los modelos de crecimiento por lo general han utilizado elementos como el trabajo, el capital, el capital humano, los recursos naturales, los avances tecnológicos, el ahorro interno, el ahorro externo, entre otros, para explicar el crecimiento.

Sin embargo, y puesto que el periodo de estudio es relativamente corto, fue importante focalizar el análisis hacia los determinantes del crecimiento económico en el corto plazo o por el lado de la demanda (como lo abordan los enfoques desde la vertiente keynesiana) para una economía abierta (Jiménez, 2010).

Así, fue conveniente la consideración de variables tales como la formación bruta de capital (variable flujo del stock de capital), el gasto público(proxy de formación de capital público), el indicador de apertura económica(proxy de relación de la economía con el extranjero), la cartera financiera (tamaño del sistema financiero) y la inversión extranjera directa (hace parte del financiamiento extranjero de la acumulación de capital) determinantes del crecimiento económico en Colombia para el periodo 2000-2010; sin embargo, no se considera al consumo como variable exógena para evitar la causalidad inversa, es decir, dada una explicación del ingreso al consumo no es adecuado establecer el crecimiento del consumo como explicativa del crecimiento del ingreso.

Ahora, una de las características importantes de la IED es que funciona como 
ahorro externo generador de rendimientos dentro de la economía doméstica, donde el ahorro tiene importantes efectos en el corto plazo sobre aumentos en el producto por la cadena de financiación e inversión (Antúnez, 2009). De la misma manera, el traspaso tecnológico que lleva consigo se traduce en avances cualitativos y cuantitativos del fondo social de conocimiento sobre los mecanismos y técnicas de la producción, lo cual afecta al crecimiento económico interno (Antúnez, 2009). De manera similar, la teoría de Harrod (citado por Antúnez, 2009), señala que la inversión, como incrementos en el stock de capital (FBK), es fundamental para el crecimiento de una economía en el largo plazo ya que estas inversiones contribuyen a aumentar la productividad laboral, con la cual se aumenta el nivel del producto (Antúnez, 2009). No obstante, para el análisis de corto plazo se utiliza la FBK, que es un flujo, diferente al acervo de capital que se usa para el análisis de largo plazo, dado que es un stock; el cual impacta igualmente en los diferentes sectores donde se intensifique, generando mayor competitividad, haciendo más eficiente el uso de los factores y, consecuentemente, impactando sobre el crecimiento económico (Antúnez, 2009).

Por otra parte, los movimientos de la cartera financiera, los movimientos crediticios en una economía, llegan a ser un importante factor de impulso inversionista y financiamiento para los agentes económicos, así como un indicador de consumo doméstico y de sus consecuentes efectos dinamizadores en los procesos económicos en el corto plazo. Como lo argumenta Keynes (1936) en su teoría general, el consumo (junto a la inversión) es uno de los determinantes de la demanda de bienes de consumo y de producción, lo que implica que esta, la demanda efectiva, determinaría la producción efectiva.

El gasto público también provoca aumentos en la demanda agregada ya que dentro del mercado se producen excesos de demanda de bienes que dan lugar a una disminución de existencias y, consecuentemente, a aumentos en la producción (Antúnez, 2010). Esto, desde los planteamientos teóricos de Hicks (citado por Antúnez, 2010), implica que el gasto público afecta los niveles de empleo y con ello la capacidad de consumo privado de los individuos y agentes económicos dentro de la economía, lo que impulsa el crecimiento total del producto $\mathrm{y}$, asimismo, explicarlo.

Finalmente, y para completar el análisis de algunos de los determinantes del crecimiento económico bajo diferentes enfoques, la dinámica comercial de una economía abierta con el exterior resulta una condición necesaria para la obtención de mayores tasas y hasta "milagros" del crecimiento (Ministerio de Comercio, Industria y Turismo, 2013) $)^{22}$. Esto significa que la transmisión de los beneficios

22 Hace referencia a crecimientos en países subdesarrollados y no exportadores de petróleo que registran tasas por encima de $3 \%$ anual (Ministerio de Industria y Turismo, 2013). 
de la apertura económica (incrementos en eficiencia, competitividad, el acceso a nuevas tecnologías y la especialización) se ha establecido como una estrategia robusta para el crecimiento del producto de una economía desde el corto plazo (Ministerio de Comercio, Industria y Turismo, 2013).

\section{- Metodología de la estimación}

Se realizó un ejercicio econométrico considerando variables que servirían de explicación al comportamiento del crecimiento de la economía colombiana (medida a través del PIB) en el corto plazo, junto con la variable de interés, la IED, orientado a observar su contribución en diferentes escenarios del modelo principal dentro de un horizonte de once años con datos trimestrales para el periodo 2000-2010, de donde se obtuvieron 44 observaciones. Los datos fueron obtenidos principalmente de dos fuentes: Las bases de datos del Banco de la República y del Departamento Administrativo Nacional de Estadística, DANE.

La técnica econométrica usada fue mínimos cuadrados ordinarios (MCO) para estimar diferentes relaciones entre las variables observadas, siendoque MCO cumple las propiedades del modelo clásico de regresión lineal (MCRL), obteniendo estimadores
MELI (mejores estimadores lineales e insesgados).

Particularmente, los datos con los cuales se trabajó la inversión extranjera corresponde a la IED bruta, es decir, aquella que corresponde al total de las afluencias de capital externo a la economía que lo recibe, sin descontar las salidas del mismo, donde en ese caso se haría referencia a la IED neta; igualmente, a estos montos se les descontaron los giros de las utilidades al extranjero, con el propósito de tener presente la totalidad de sus efectos y alcances dentro del análisis.

Igualmente, y para el caso de los datos de las variables IED y FBK, se trabajó con el deflactor de la formación bruta de capital (con valores constantes en base 2005) y los valores corrientes y constantes con base 2005 del PIB, ya que la disponibilidad de datos así lo facilitaba. Finalmente, todos los valores de cada uno de los datos con los que se contó se llevaron a pesos colombianos utilizando la tasa representativa del mercado (TRM) promedio trimestral, para manejar los saldos en una misma moneda.

\section{- El modelo econométrico}

Con base en el análisis anterior se define el siguiente modelo teórico:

$$
g_{t}=\beta_{1}+\beta_{2} \text { ied }_{t-1}+\beta_{3} f_{b k_{t}}+\beta_{4} g p_{t}+\beta_{5} \text { gae }_{t-1}+\beta_{6} \text { cartera }_{t-1}+\mu_{t}
$$


La variable endógena $g_{t}$ es la tasa de crecimiento de la economía colombiana.

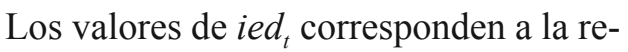
lación de los flujos de inversión extranjera directa bruta menos las salidas que se hacen efectivas por concepto utilidades y dividendos respecto a la FBK en pesos a precios de $2005^{23}$.

Se hace el descuento de las salidas de utilidades y dividendos para obtener un indicador más preciso de los flujos del capital exterior, por cuanto se pretende abordar el análisis desde el impacto de la IED sobre la formación bruta de capital y así, consecuentemente, sobre la inversión y el crecimiento de la economía. En este sentido, mayores flujos de capital externo por IED, reflejados directamente como participación en la formación bruta de capital, afectarían positivamente el crecimiento del producto interno bruto de la economía. De igual forma, si la participación de la IED dentro de la inversión total de la economía se redujera, por medio de la ecuación se esperaría que el nivel de crecimiento disminuyera para el periodo siguiente.

La $f b k_{t}$ señala la relación de la formación bruta de capital respecto al PIB menos el valor de la IED respecto al PIB, por tanto, se espera que si la participación de la inversión es mayor, esto se reflejará en la tasa de crecimiento; sin embargo, si la participación de la inversión es menor, esto podría afectar los niveles de crecimiento de la economía colombiana dentro del periodo analizado. Esta variable es fundamental, dado que si la IED afecta positivamente al crecimiento económico, la FBK debe tener un efecto positivo.

Se adicionan algunas variables control como: la participación del gasto público del gobierno central en el PIB total $\left(g p_{t}\right)$, el indicador de apertura comercial $\left(\right.$ gae $\left._{t}\right)$, y la participación de la cartera bruta en el $\operatorname{PIB}\left(\right.$ carter $\left._{t}\right)$. En general, se llevó a cabo este análisis esperando que las variables $f b k_{t}$ y $g p_{t}$ impactaran inmediatamente a la variable endógena mientras que, las variables ied , gae $_{t}$ y cartera , $_{t}$ que presentan rezago, impactaran al crecimiento del producto interno bruto en un periodo posterior.

En cuanto a la clasificación del modelo, el modelo es aleatorio, ya que contiene variables probabilísticas que están conformadas por aquellas variables que afectan la variable endógena, pero cuyo valor no está predeterminado sino que se conoce mediante procesos de probabilidad $\left(\mu_{t}\right)$; es completo, ya que tiene una ecuación y una variable endógena, es decir el número de ecuaciones es igual al número de variables endógenas; y es lineal, ya que sus variables y parámetros están elevados a una potencia igual a 1(Gujarati, 2001).

\section{- Resultados}

Inicialmente, la estimación de la regresión se realizó adicionando cada variable

23 El deflactor de la FBK corresponde a los montos trimestrales de formación bruta de capital a precios corrientes sobre los montos trimestrales de formación bruta de capital a precios constantes en base al año 2005. 
a la vez para observar el comportamiento de los modelos en general y de la variable IED en particular.

Para esta regresión, la variación del crecimiento económico en el periodo 2000 2010 es explicada en un $24.39 \%$ por el conjunto de las variables IED, formación bruta de capital, gasto público, apertura económica y cartera; el $75.61 \%$ restante de la variabilidad estaría determinada por variables no explícitas en el modelo que son recogidas en la variable aleatoria. Para elegir el modelo de regresión adecuado se siguió los criterios Shwarz (CIA) y Akaike (CIS), por lo que podemos inferir que este es el más apropiado para el análisis ya que nos señala la mejora en cuanto a la bondad del ajuste al incluir todas las variables propuestas.

Tabla 2. Regresión del efecto de la IED sobre el crecimiento económico colombiano (2000-2010)

\begin{tabular}{|c|c|}
\hline \multirow{2}{*}{ Constante } & Variable dependiente: tasa de crecimiento del PIB \\
\cline { 2 - 2 } & Periodo 2000-2010 \\
\cline { 2 - 2 } Inversión extranjera directa (-1) & 0.024733 \\
& {$[0.025714]$} \\
Formación bruta de Capital & $0.018947^{* *}$ \\
& {$[0.0082229]$} \\
Gasto público & $0.199352^{*}$ \\
& {$[0.110857]$} \\
Apertura económica (-1) & $0.181697^{*}$ \\
& {$[0.103828]$} \\
Cartera financiera (-1) & $-0.196777^{*}$ \\
& {$[0.121291]$} \\
& -0.006773 \\
Observations & {$[0.008749]$} \\
R-squared & 44 \\
Durbin-Watson stat & 0.243909 \\
& 2.376584 \\
\hline
\end{tabular}

* Significativo al $5 \%$.

** Significativo al $10 \%$.

En este ejercicio de estimación, la prueba de significancia global indicó que, con un nivel de confianza de $90 \%$ y una significancia de $10 \%$, las variables IED, gasto público, cartera financiera, apertura económica y formación bruta de capital sí tienen impacto sobre el crecimiento del PIB en el periodo estudiado. Respecto a las significancias individuales, los resultados sugieren que, con un nivel de significancia de $5 \%$, la variable IED sí manifestó efecto sobre el crecimiento del 
PIB en el periodo 2000-2010; asimismo, con significancia de $10 \%$, las variables explicativas FBK, GP y GAE tienen impacto sobre la endógena.

De la misma manera, se realizaron pruebas de hipótesis para comprobar los supuestos que van tras la elaboración del modelo de regresión. Así, los resultados arrojados por el test Breusch-Pagan-Godfrey para el supuesto de homocedasticidad, donde la probabilidad Chi-cuadrado $(5)=0.8594$ es mayor a 0.05 es decir la probabilidad de $5 \%$ de cometer el error tipo I (rechazar la hipótesis nula), por lo que se aceptó la hipótesis nula y con un $95 \%$ de confianza, indicó que el modelo no presenta heterocedasticidad, es decir, que la varianza del modelo se mantiene constante. El test Breusch-Godfrey para el análisis de no autocorrelación de los residuos indica que, con un nivel de confianza de $95 \%$, no se presenta correlación de los errores en el tiempo. Respecto a la correcta especificación, la prueba llevada a cabo mediante el método Reset de Ramsey indicó que con un $95 \%$ de confianza, era conveniente aceptar la hipótesis nula, la cual argumenta que los estimadores son insesgados y consistentes para muestras asintóticas.

Un test para probar la inexistencia de una regresión espuria es el de raíz unitaria, la cual se llevó a cabo mediante la prueba de Dickey-Fuller aumentada (DFA), teniendo como hipótesis nula la existen- cia de raíz unitaria frente a la negación con la alterna, pretendiéndose verificar la estacionariedad de los residuos que comprueba la existencia de una relación de equilibrio de las variables a largo plazo. En tanto, si el valor p de la prueba DFA es 0.00 , entonces, la hipótesis nula es rechazada al $1 \%$, por lo que no hay presencia de raíz unitaria en los residuos y la regresión no es espuria.

\section{- Relación entre variables}

Dentro del comportamiento de las variables, el signo de los coeficientes de la estimación que evalúa la relación entre el crecimiento e inversión es el esperado, indicando que aumentos en la inversión extranjera directa tiene un efecto positivo sobre la tasa de crecimiento; esto es, si la IED aumenta, el crecimiento del PIB también, lo que corrobora muchos de los planteamientos que han arrojado otros estudios $^{24}$.

La relación entre la formación bruta de capital y el crecimiento del producto es directa. A medida que incrementa la FBK, el PIB también aumenta. Esta relación confirma algunos de los principales planteamientos teóricos definidos.

La relación entre el gasto público y el crecimiento del PIB resulta directa, lo que significa que a medida que aumenta el gasto público, el crecimiento del PIB aumenta.

24 Tal es el caso del estudio del impacto de la IED en Colombia llevado a cabo por Fedesarrollo (2007). 
Tanto la relación entre la apertura económica y el crecimiento del PIB como la relación entre los movimientos en la cartera bruta y el crecimiento del PIB, es inversa (-). Un aumento en la apertura provocará una disminución en el crecimiento de la economía. Igual sucede con la cartera bruta, lo que contradice la relación directa entre estas variables que argumenta la teoría. Esto supone un rompimiento teórico de los principales planteamientos macroeconómicos, ya que la teoría señala una relación positiva entre estas variables. Este hecho puede ser explicado debido a que la temporalidad escogida puede limitar el cumplimiento de las posiciones teóricas.

En cuanto a los resultados más relevantes, y como se puede observar en la Tabla 2, el estimador $\beta_{2}=0.018947$ es el coeficiente de regresión parcial que mide el efecto promedio en el crecimiento del PIB para el periodo 2000-2010 explicado por los flujos de IED, manteniendo constantes el gasto público, la apertura económica y la cartera financiera. El valor del Durbin Watson, que es mayor al $\mathrm{R}^{2}$, es un buen indicio de que la regresión no es espuria ${ }^{25}$. En este sentido, cuando la participación dentro de la FBK de la IED menos la salida de las utilidades aumenta en un 1\% en un trimestre, el crecimiento del producto interno bruto aumentó en $0.019 \%$ en el trimestre siguiente; o lo que es lo mismo, por cada $1 \%$ de incremento en la IED respecto a FBK durante el año el crecimiento de la economía seria $0.076 \%$ superior, en ese sentido, una ied de $20 \%$ durante el año lleva a que el crecimiento anual adicional sea $1.52 \%$.

En este contexto se presenta un cumplimiento lógico dentro del modelo, dado que tanto ied como $f b k$ afectan al crecimiento económico, dado que la IED hace parte de la FBK. Entonces, siguiendo esta lógica, para un periodo de alto crecimiento se infiere que los aumentos en la IED perturbaron al crecimiento económico en cuanto este se vio afectado por los niveles de inversión. Ambas variables, por su relación, afectan en el mismo sentido el crecimiento del PIB.

\section{Análisis sectorial}

Con el ánimo de complementar el ejercicio anterior, se llevó a cabo un análisis sobre diferentes sectores que permitieran identificar la importancia y el impacto relativo que puede tener un sector productivo, altamente relacionado con los flujos de IED, sobre el resto de las ramas de la actividad económica mediante encadenamientos hacia adelante -a través de la demanda por insumos productivos que ayudan a aumentar su producción- o de encadenamientos hacia atrás -a través de la venta de sus productos como insumos que contribuye a la expansión de otras ramas de actividad-.

\footnotetext{
$\overline{25}$ Cuando se efectúa una regresión de una variable de serie de tiempo sobre otra variable de serie de tiempo, se puede dar una $\mathrm{R}^{2}$ elevada aunque no exista una relación significativa entre las variables. En ese caso puede darse problemas de regresión espuria (Gujarati, 2001).
} 
Con los encadenamientos hacia adelante se pretende evaluar la venta de los bienes para la expansión de la capacidad productiva de otros sectores, ver cómo estos "empujan" a otros sectores a través de la venta de insumos de producción; y con los encadenamientos hacia atrás evaluar la compra de bienes de otros sectores para incrementar la producción de una rama específica que "impulsa" a otros por la compra de insumos (Fedesarrollo, 2007). La herramienta de los encadenamientos llega a ser muy útil en cuanto permite cuantificar el impacto de los flujos de IED, permitiendo establecer la magnitud de respuesta de las diferentes actividades productivas frente a variaciones en las dinámicas de los sectores que se encuentran profundamente ligados a estas inversiones, en un corto plazo.

Para esto, es fundamental contar con la información de las interacciones entre los diferentes tipos de actividades con la que cuenta la matriz insumo-producto, en la cual se presentan para un sector específico el total de lo que un sector produce, tanto para consumo intermedio como para producto final. Con esta matriz es posible identificar los vínculos entre las diferentes ramas de actividad productiva respecto a qué sectores sirven como insumo y qué sectores se benefician de determinado sector en particular con sus insumos (Hernández, 2012).

Para la realización de este ejercicio, primero, se utilizó la información proveniente de la matriz simétrica total de insumo-producto, producto por producto, base 2005 publicada por el DANE. Para realizar la construcción de la matriz insumo-producto fue necesario analizar la matriz de coeficientes técnicos (A) y la matriz de importaciones (M).

En ese sentido, para construir la matriz insumo-producto (L) o de Leontief se tiene:

$$
L=(I-A+M)^{-1}
$$

La matriz de multiplicadores (L) es calculada como la inversa de la diferencia entre la matriz identidad (I) y la suma entre la matriz de coeficientes técnicos y la de importaciones.

Particularmente, se trabajó sobre dos de los sectores en los cuales los flujos de IED en promedio han sido mayores de la década, con datos deflactados a precios de 2005 dado que la matriz base es de 2005 . Sin embargo, para cada caso se tomó un año pico (el que mayor inversión extranjera recibió) y un año valle (en el que menores flujos se registraron) de acuerdo a los antecedentes históricos; esto con el fin de tener una observación amplia de los impactos de estos flujos en los diferentes sectores de la economía colombiana a lo largo de su historia económica y bajo las diferentes $-\mathrm{y}$ marcadas- políticas de apertura.

No obstante, es importante tener en cuenta que esta metodología presenta limitaciones y condicionantes que la enmarcan únicamente como una herramienta complementaria. Así en estos ejercicios se suponen relaciones de proporcionalidad 
entre los insumos y el producto, esto es, se supone implícitamente que las tecnologías de producción de todos los sectores son fijas (constantes), por lo que no se tiene en cuenta las reacciones de productores ante cambios en los precios (Fedesarrollo, 2007).

Dentro de la simulación, se trabajó con el sector petrolero y el de carbón mine- ral, los cuales representaron importantes participaciones frente a los flujos de inversión extranjera directa durante la década y, de la misma manera, sectores con importantes encadenamientos, hacia adelante y hacia atrás. Estos flujos se tomaron en miles de millones de pesos a precios de 2005, y se asumieron incrementos en la formación bruta de capital en el sector correspondiente.

Tabla 3. Simulación del impacto del sector petróleo

\begin{tabular}{|c|c|c|c|c|c|}
\hline \multirow[b]{2}{*}{$\begin{array}{l}\text { MILES DE } \\
\text { MILLONES } \\
\text { DE PESOS } \\
\text { DE } 2005\end{array}$} & \multicolumn{5}{|c|}{ IMPACTO SECTOR PETRÓLEO } \\
\hline & $\begin{array}{c}\text { Petróleo crudo, } \\
\text { gas natural y } \\
\text { minerales de } \\
\text { uranio y torio }\end{array}$ & $\begin{array}{l}\text { Ptos de la } \\
\text { refinación } \\
\text { del petróleo; } \\
\text { combustible } \\
\text { nuclear }\end{array}$ & $\begin{array}{c}\text { Servicios de } \\
\text { transporte } \\
\text { terrestre }\end{array}$ & $\begin{array}{c}\text { Remuneración } \\
\text { de los } \\
\text { asalariados }\end{array}$ & $\begin{array}{l}\text { Excedente } \\
\text { bruto de } \\
\text { explotación }\end{array}$ \\
\hline 2000/Año & -913.07 & -10.25 & -69.45 & 72.17 & -680.56 \\
\hline valle de IED & $-5.536 \%$ & $-0.084 \%$ & $-0.297 \%$ & $-0.066 \%$ & $-0.602 \%$ \\
\hline 2008/Año & 8558.07 & 96 & 650.92 & 3 & 6378.83 \\
\hline pico de IED & $51.89 \%$ & $0.78 \%$ & $2.779 \%$ & $0.003 \%$ & $5.642 \%$ \\
\hline
\end{tabular}

Fuente: elaboración de los autores.

Teniendo en cuenta las consideraciones anteriores y con base en las estadísticas del DANE y del Banco de la República, se cuantificó el efecto de la IED que entró en dos años clave hacia el sector petrolero. En el año 2000 estos flujos fueron los más bajos dentro de la década, con un total de $-\$ 831,746$ millones de pesos $^{26}$, por lo que, de acuerdo con la matriz insumo producto y los resultados de sus encadenamientos (tanto hacia adelante como hacia atrás), la desinversión en el sector petróleo generó pérdidas en la producción de $\$ 913.000$ millones de pesos (disminución de 5.5\%). Vale aclarar que este tipo de choques generaron réplicas hacia adelante o hacia atrás, siendo el sector de servicios de transporte terrestre el que sufriómayores pérdidas en su producción (alrededor de \$69.000 millones de pesos), así como una disminución en el excedente bruto de explotación de $\$ 680.000$ millones de pesos.

$\overline{26}$ Un flujo negativo significa que los reembolsos de capital son mayores a la nueva inversión (Banco de la República). 
Por el contrario, en el año 2008 los flujos fueron los mayores de la década en el sector, alcanzando un monto de $\$ 7,795.000$ de millones de pesos, lo que dentro de la simulación aumenta su producción en $\$ 8,558.000$ millones de pesos, y el excedente bruto de explotación en \$6,378.000de millones de pesos. Pero, como en general estas dinámicas impactan - directa o indirectamente- a prácticamente toda la economía, muchos otros sectores también se afectan. Los productos de caucho y plástico, las sustancias y productos químicos, maquinaria y equipo, la energía eléctrica, los servicios de reparación de automotores, de artículos personales y domésticos, el comercio, los servicios de alojamiento y suministro de comidas, los servicios de intermediación financiera y seguros, los impuestos, etc., son ejemplos de los sectores que se interrelacionan con el sector petróleo y que sienten sus cambios dentro de la simulación.

Otro ejercicio (que podría extenderse a cada uno de los sectores receptores de IED utilizando la misma lógica interpretativa) se realizó con el sector de minas y canteras (incluyendo carbón mineral). Como se puede ver en la Tabla 4, el año que menor flujo de IED registró el sector fue en el 2001, con $\$ 936$ miles de millones de pesos, los cuales impactaron principalmente sobre su propia producción, los servicios de transporte terrestre (con aumentos en su producción de $0.17 \%$ ), los trabajos de construcción, obras civiles y servicios de arrendamiento de equipo con operario $(0.18 \%)$, los servicios complementarios y auxiliares al transporte $(0.7 \%)$, el excedente bruto de explotación $(0.6 \%)$, entre otros.

Tabla 4. Simulación del impacto del sector

\begin{tabular}{|c|c|c|c|c|c|}
\hline \multirow[b]{2}{*}{$\begin{array}{l}\text { MILES DE } \\
\text { MILLONES } \\
\text { DE PESOS } \\
\text { DE } 2005\end{array}$} & \multicolumn{5}{|c|}{ IMPACTO CARBÓN MINERAL } \\
\hline & $\begin{array}{l}\text { Carbón } \\
\text { mineral }\end{array}$ & $\begin{array}{c}\text { Servicios de } \\
\text { transporte } \\
\text { terrestre }\end{array}$ & \begin{tabular}{|c} 
Trabajos de \\
construcción, \\
obras civiles \\
y servicios de \\
arrendamiento \\
de equipo con \\
operario
\end{tabular} & \begin{tabular}{|c|} 
Servicios com- \\
plementarios \\
y auxiliares \\
al transporte
\end{tabular} & $\begin{array}{l}\text { Excedente } \\
\text { bruto de } \\
\text { explotación }\end{array}$ \\
\hline 2001/Año & 948.45 & 40.24 & 37.82 & 31.18 & 650.81 \\
\hline valle de IED & $15.278 \%$ & $0.172 \%$ & $0.178 \%$ & $0.677 \%$ & $0.576 \%$ \\
\hline 2009/Año & 6018.6 & 241.27 & 226.74 & 186.96 & 3901.89 \\
\hline pico de IED & $96.949 \%$ & $1.030 \%$ & $1.066 \%$ & $4.060 \%$ & $3.451 \%$ \\
\hline
\end{tabular}

Fuente: elaboración de los autores. 
El año punta de IED sobre el sector de minas y canteras en la década fue el 2009 , cuando los flujos alcanzaron un monto de $\$ 5,615.000$ de millones de pesos. Junto con los sectores expuestos en la Tabla 4, este sector impactaría con fuerza en los sectores de refinación de petróleo y combustible nuclear, sustancias y productos químicos, energía eléctrica, servicios de reparación de automotores, de artículos personales y domésticos, los servicios de intermediación financiera, de seguros y servicios conexos, los servicios a las empresas (excepto servicios financieros e inmobiliarios), la remuneración de los asalariados, impuestos, entre otros.

\section{CONCLUSIONES}

Gran parte de la literatura económica señala que, en términos generales, la IED tiene importantes efectos de diversa índole y magnitud sobre la economía del país receptor a través de canales directos e indirectos como los spillovers o las cadenas productivas hacia atrás o hacia adelante. Dentro de los principales efectos sobre la dinámica económica del país al que llega la IED, se puede encontrar los dirigidos hacia la formación bruta de capital (inversión), el desarrollo tecnológico, la mejora en la productividad de los sectores asociados, el comercio internacional, los mayores procesos de innovación, el crecimiento del empleo, la disponibilidad de recursos de financiación, el desarrollo de mercados internos, entre otros.
Sin embargo, sus impactos también se extienden hacia el desplazamiento de las empresas nacionales, las alteraciones culturales y sociales, la explotación de recursos nacionales y la concentración de los ingresos, especialmente en los países en desarrollo. Esto depende, entre otros factores, del objetivo estratégico de la inversión (de si la IED está enfocada a la explotación del mercado doméstico, a la explotación de sus recursos naturales, a la adquisición de activos claves o al uso de la economía receptora como plataforma exportadora) y de las condiciones de las economías receptoras.

En Colombia, entre los años 2000 y 2010, con la legislación y los planes de desarrollo se empezaron a fortalecer las condiciones facilitando la entrada del capital extranjero y su progresivo posicionamiento dentro de la economía nacional. Es así como a lo largo de esta década, la IED registró una tendencia creciente a pesar de las fluctuaciones que el clima económico mundial generó $\mathrm{y}$, de la mano del crecimiento económico, esta relación se mantuvo en tasas positivas de crecimiento. Por ello, la IED se convirtió en una de las principales fuentes de financiación, en un importante determinante de la cuenta de capital y la oferta y demanda de divisas en el mercado cambiario; sus efectos también se evidenciaron en mejoras en el empleo, la transferencia de tecnología y la diversificación en sectores de exportación. 
No obstante, la relación entre el monto de la inversión extranjera directa que ha llegado a Colombia y los egresos por pago de utilidades y dividendos entre los años 2000 y 2010 , se ha venido reduciendo. $\mathrm{Al}$ inicio del periodo esta presentaba una tendencia uno a uno, pero al final de la década ya fue mayor la salida por rentas que las entradas por inversión de capital. La relación indicó que ya era mayor lo que se giraba que lo que se invertía en Colombia.

Es por ello que el análisis hecho en este estudio para observar el efecto de la IED sobre el crecimiento económico en el periodo delimitado, se trabajó, a diferencia de otros estudios, a partir de esta relación entre los montos de inversión extranjera y las salidas por utilidades de los mismos. Para esta finalidad, se trabajó un modelo econométrico por MCO y, complementario a esto, se realizó una simulación del impacto sectorial de la IED usando la matriz insumo-producto de Colombia.

El resultado de la estimación realizada con el método de mínimos cuadrados ordinarios muestra que, de una parte, la IED tuvo efectos positivos sobre el crecimiento de la economía colombiana a lo largo del periodo 2000-2010, a pesar de las crecientes salidas por concepto de utilidades y dividendos. Este efecto se reflejó en la explicación del crecimiento económico en alrededor de $0.00072 \%$ por la inversión extranjera directa en promedio anual. Por otra parte, las variables macroeconómicas $f b k$ y cartera financiera se comportaron como determinantes del crecimiento económico, con efectos positivos (como se esperaba) para el periodo analizado. De la misma manera, el índice de apertura económica y el gasto público explicaron el crecimiento de la producción para la década; sin embargo, la relación estuvo determinada por signos negativos, lo cual podría explicarse por la corta temporalidad con la cual se trabajó.

El anterior análisis se complementó con una simulación de encadenamientos sectoriales usando la matriz insumoproducto para Colombia. Los principales resultados sugieren que los sectores que son impulsados por la IED bajo su composición actual (en el ejercicio a sectores dirigidos como los recursos hacia la explotación de petróleo y carbón mineral), benefician indirectamente a otros sectores mediante su papel como impulsadores de la actividad económica a través de la compra y venta de insumos. Además, con esta simulación se pudo detectar los sectores en los cuales sería más productivo la focalización de este tipo inversiones mediante el tamaño de los encadenamientos; infiriendo que, por ejemplo, sectores con mayor valor agregado como el industrial y el manufacturero, con encadenamientos más robustos hacia adelante y hacia atrás, podría mejorar la calidad del direccionamiento de los recursos por IED. 
Efectos de la inversión extranjera directa sobre el crecimiento económico ...

María Luz Moyano Buitrago - José Mauricio Gil León

\section{REFERENCIAS}

1. Álvarez, A., Barraza S. \& Legato, M. (2009). Inversión extranjera directa y crecimiento económico en Latinoamérica. La Mancha:Universidad de Castilla.

2. Antúnez, C. I. (2009). Crecimiento económico. Modelos de crecimiento económico. Lima, Perú: Editorial Universidad de San Marcos.

3. Banco de la República (2010). Flujos de inversión desde y hacia Colombia: conceptos, medición y su comportamiento en 2009. Reportes del Emisor (131).

4. CEPAL Comisión Económica para América Latina y el Caribe. (2004). La inversión extranjera. México: Organización de las Naciones Unidas.

5. Coleman, T. (2012). Tendencias e impactos de la inversión extranjera en Colombia. Tesis de postgrado. Bogotá: Universidad EAN.

6. Cubillos, M. \& Navas, V. (2000, junio). Inversión extranjera directa en Colombia: características y tendencias. Boletines de divulgación económica, (4).

7. Dunning, J. (2001). El paradigma ecléctico de la producción internacional: pasado, presente y futuro. Gran Bretaña: Edward Elgar Publishing.

8. Fajnzylber, F. (1976). Las empresas transnacionales: expansión a nivel mundial y proyección en la industria mexicana. México: Fondo de Cultura.

9. Fedesarrollo (2007). Impacto de la inversión extranjera en Colombia: situación actual y perspectivas. Bogotá D.C: Editorial Fedesarrollo.

10. Garavito, A., Iregui, M. \& Ramírez, M. (2012). Inversión extranjera directa en Colombia: evolución reciente y marco normativo. Borradores de Economía. Bogotá: Banco de la República de Colombia.

11. Guerra, A. (2001).Factores determinantes de la inversión extranjera: introducción a una teoría inexistente. México D.F: UNAM.

12. Gujarati, D. N. (2001). Econometría. (4 ed.). México D.F: McGraw-Hill Interamericana.

13. Hernández, G. (2012). Matrices insumo-producto y análisis de multiplicadores: una aplicación para Colombia. Revista de economía institucional, 14(26).

14. Ibarra, D. (2004). La inversión extranjera. México: Comisión Económica para América Latina y el Caribe, CEPAL. 
15. Jiménez, F. (2010). Crecimiento económico: enfoques y modelos. Pontificia Universidad Católica del Perú, Departamento de Economía y Cartolan Editora.

16. Keynes, J. M. (1936). Teoría de la ocupación, el interés y el dinero. México D.F: Fondo de Cultura Económica.

17. Krugman, P., Obstfeld, M. \& Melitz, M. (2001). Economía internacional. Teoría y política. (9 ed.). Madrid: Prentice Hall.

18. Lahiri, S. (2009). Foreign direct investment: an overview of issues. International of Economics and Finance, 18(1), 1-3.

19. Lensink, R. (2003). Inversión extranjera directa, desarrollo financiero y crecimiento económico. The Journal of Development Studies, volume 40, número 1, págs 142-163.

20. Lipsey, R.E. (2000). The role of foreign direct investment in international capital Fflows. NBER WorkingPaper.

21. Ministerio de Comercio, Industria y Turismo (2013). Apertura económica y crecimiento. Recuperado de http://www.mincit.gov.co/publicaciones.php?id=11202

22. Murra, S. (2006). Revaluando la transmisión de spillovers de la IED: un estudio de productividad para Colombia. Desarrollo y Sociedad, CEDE, Universidad de los Andes.

23. Proexport (2007). Impacto de la inversión extranjera en Colombia: situación actual y perspectivas. Bogotá: Editorial Proexport.

24. Ramírez, J. \& Rincón, V. (2010). Empresas multinacionales y su impacto en la economía de Pereira: sector industrial. Tesis de pregrado. Universidad Católica Popular de Risaralda.

25. Suárez,A. (2010). Confianza inversionista. Economía colombiana, primera década del siglo XXI. Bogotá D.C:Aurora.

26. Steiner, R. \& Giedion, U. (1995). Características, determinantes y algunos efectos de la inversión extranjera directa en Colombia. Bogotá: Fedesarrollo. 
